\title{
Gestão Técnica de Edifícios com KNX
}

\section{Enquadramento}

A eficiência energética dos edifícios é cada vez mais uma das prioridades nas agendas dos gestores comercias dos edifícios e proprietários. Em parte deve-se ao processo de certificação energética dos edifícios, que entrou em vigor em 2007, através dos Decretos de Lei 78/2006, 79/2006 e 80/2006. A solução passa agora pela poupança contínua de energia através de uma eficiente Gestão Técnica de Edifícios.

\section{Standard KNX}

O Standard KNX (anteriormente EIB) é um sistema para o controlo e automação de todo tipo de Edifícios, totalmente compatível com a Norma Europeia EN50090.

Grande parte dos proprietários de edifícios comerciais, ao nível mundial, rapidamente aceitou esta tecnologia como suporte para alcançar a máxima eficiência energética, uma vez que tem uma série de vantagens em relação a soluções alternativas. Por exemplo, num momento em que é esperado que a Gestão Técnica de Edifícios (BEMS - Building Energy Management Systems) seja cada vez mais a solução adoptada, o KNX tem a capacidade de ser integrado em qualquer tipo de BEMS. Uma vez integrado, outras vantagens do KNX entram em jogo no controlo local em cada área do edifício.

A vantagem do KNX cobrir praticamente todas as áreas funcionais de um edifício, oferece-nos uma abordagem holística da utilização eficiente da energia. O KNX não está limitado à iluminação, aquecimento ou medição, ou qualquer outra função específica.

A plataforma KNX tem sido adoptada por muitos e altamente respeitados fabricantes, oferecendo uma vasta escolha de produtos que abrangem todas as áreas funcionais dos edifícios.
A escolha um protocolo proprietário de um único fabricante, obriga a uma dependência que poderia ser problemática durante o ciclo de vida de um sistema.

Com o KNX, se um determinado produto já não está disponível, existe a garantia que haverá uma alternativa de substituição.

Como o KNX abrange uma diversidade de aplicações que utilizam o mesmo protocolo de comunicações, a ligação em rede dos dispositivos é muito simples. Um único cabo par entrançado pode, em muitas vezes, ser suficiente para interligar vários dispositivos que operam em conjunto numa única rede. O KNX utiliza como suporte físico o cabo verde J$\mathrm{Y}(\mathrm{st}) \mathrm{Y} 2 \times 2 \times 0.8 \mathrm{~mm} 2$ (i.e. par entrançado TP), podendo contudo usar outros meios, tais como, Rádio (RF), Ethernet, Fibra Óptica ou Linha de Potência.

Como exemplo de integração do KNX, já existem vários dispositivos no mercado, designados por "gateways", que proporcionam a interligação com outros protocolos de controlo, tais como DALI (Digital Addressable Lighting Intelligence). Estes dispositivos, são utilizados para expandir a capacidade dos sistemas de controlo KNX e fornecer a solução de gestão completa de um edifício.

KNX também tem trabalhado com protocolos ao nível da gestão, como o BACnet, para permitir o interfuncionamento entre estas duas normas, sempre que o projecto exige gestão centralizada.

Consultores, especialistas e utilizadores finais à procura de soluções abertas para Gestão Técnica de Edifícios, estão cada vez mais a considerar KNX como tecnologia base em detrimento de soluções proprietárias ou de vários controlos baseados em hardware. 


\section{ARTIGO TÉCNICO}

O que também contribui para escolha do KNX, é que um produto que é colocado no mercado, é totalmente testado e certificado por um organismo regulador independente e só depois é que o produto pode ter o logótipo KNX.

A KNX Association é o organismo internacional responsável pela certificação. Este processo, garante total confiança na fiabilidade e interoperabilidade dos produtos KNX, independentemente dos dispositivos e fabricantes.

O novo paradigma da gestão energética, faz com que seja extremamente importante tornar mais eficiente a utilização da energia.

Por exemplo, um sistema de controlo da iluminação pode ser simplesmente configurado para acender as luzes somente quando alguém está presente na sala, mas também pode monitorar níveis luminosidade e regular a iluminação (escurecer ou clarear) em função da luz natural. Este é um exemplo muito simples de eficiência energética.

O controlo eficaz da iluminação pode resultar em economias de energia muito significativas. Se o sistema for integrado com o controlo de estores e persianas, climatização e monitorização, poderá proporcionar enormes poupanças. A beleza do KNX é a capacidade de possibilitar a inclusão de mais soluções de poupança de energia, sem condicionar o normal funcionamento do edifício. Mais, sendo o KNX uma tecnologia distribuída, a avaria ou falha de um elemento não compromete o funcionamento dos restantes.

\section{Alguns Exemplos de Utilização do KNX}

Hoje em dia, o KNX é uma tecnologia adoptada em todo mundo, desde da China aos Estados Unidos, bem como da Austrália ao Médio Oriente.

Seguidamente apresentam-se alguns exemplos que representam alguns dos projectos mundiais realizados com KNX.

\section{- Inglaterra, Heathrow Airport, Terminal 5}

No terminal 5 do aeroporto de Heathrow, o KNX controla a gestão dos sistemas de iluminação, de forma a proporcionar aos passageiros um ambiente bem iluminado nas diversas áreas do terminal, incluindo o terminal ferroviário, o pátio principal do edifício e a ligação dos passageiros (TTS Tracked Transit System) entre o edifício principal e os edifícios utilizados para o embarque.

Também controla a iluminação dos vários andares do parque de estacionamento, do centro climatização e da torre de controlo de tráfego aéreo.

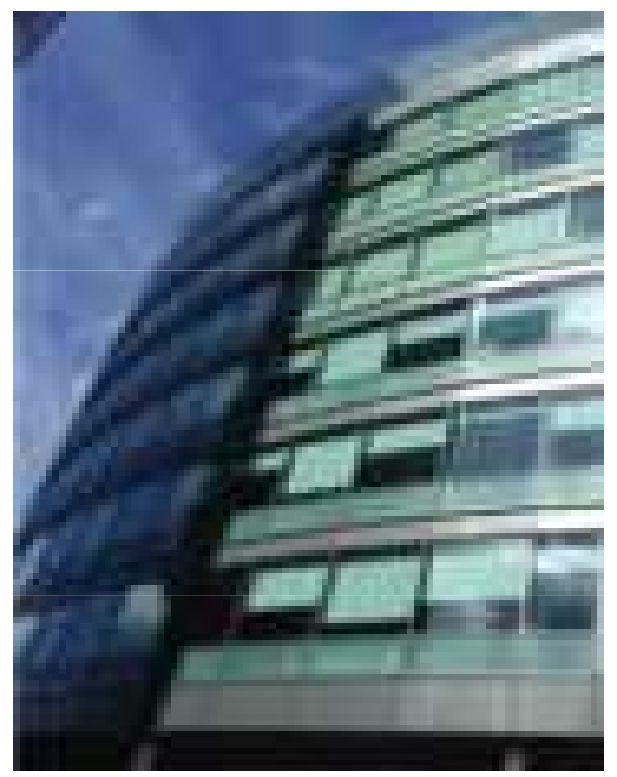

Figura 1 - Inglaterra, Heathrow Airport, Terminal 5

Embora não tenha sido desenvolvido para comunicar directamente com o Sistema de Gestão Técnica (SGT), sendo a plataforma KNX é uma tecnologia aberta, foi possível integrar o sistema KNX no SGT.

Esta solução permite à manutenção acompanhar a evolução dos sistemas de iluminação em todo o terminal e rapidamente identificar eventuais falhas através do Sistema Central de Gestão Técnica, incluindo a sua localização precisa. Desta forma, garante-se que todas as áreas do terminal estão constantemente bem iluminada, facilitando ainda a sua manutenção. 
O sistema de iluminação reage de acordo com as condições climáticas, regulando automaticamente a iluminação artificial em função da iluminação natural exterior.

Ao todo, foram instalados mais de 400 actuadores KNX para o controlo da iluminação. Em algumas áreas, existem botões de pressão que fornecem um controlo manual do sistema de iluminação, sobrepondo-se ao sistema automático de controlo. Ao anoitecer e ao amanhecer, quando o aeroporto é menos movimentado, o sistema de iluminação reduzirá automaticamente iluminação níveis.

\section{- China, Estádio Olímpico de Pequim}

As principais arenas utilizadas nos Jogos Olímpicos de Pequim estão automatizadas com a tecnologia KNX.

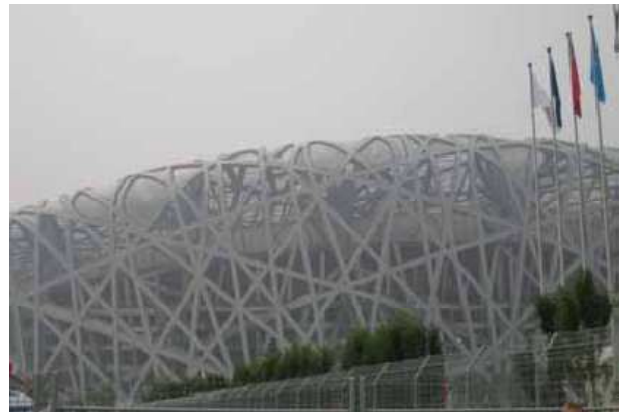

Figura 2- China, Estádio Olímpico de Pequim

No espectacular "Ninho de Pássaros", o todo sistema de iluminação é controlado por KNX, incluindo a deslumbrante iluminação exibida durante a abertura e encerramento da 29. edição dos Jogos Olímpicos de Verão.

A mesma tecnologia foi instalada no maior centro Aquático do mundo, no qual os organizadores dos Jogos investiram 100 milhões de euros.

Este edifício, utiliza a tecnologia KNX, por exemplo, para tempo de controlo e regulação do consumo de energia, assim como para os efeitos de iluminação na fachada do edifício.

\section{- Pequim, Terminal 3 do Aeroporto}

Mais de 11.000 dispositivos KNX entraram na construção do Terminal 3 do Aeroporto Internacional de Pequim, para o controlo da iluminação, climatização e transmissão de mensagens de erro.

O Terminal 3 do Aeroporto de Pequim, que possui uma área de $986.000 \mathrm{~m}^{2}$ e é o maior edifício num aeroporto no mundo, foi inaugurado em Fevereiro 2008. Actualmente, os dois mais importantes aeroportos da China - Xangai e Pequim - estão equipados com a tecnologia KNX.

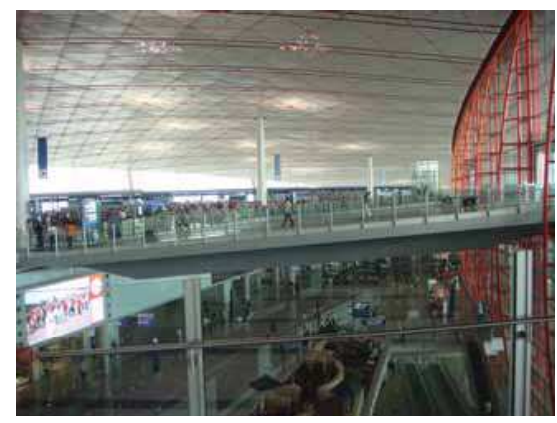

Figura 3- Terminal 3 do Aeroporto de Pequim

\section{- Turquia, Hotel Kempinski, "The Dome”}

O novo e luxuoso Hotel Kempinski, "The Dome", na paradisíaca praia de Antalya na Turquia, apresenta-se como um sonho das 1001 Noites. A arquitectura de um complexo edifício moderno faz lembrar o estilo Seljukian.

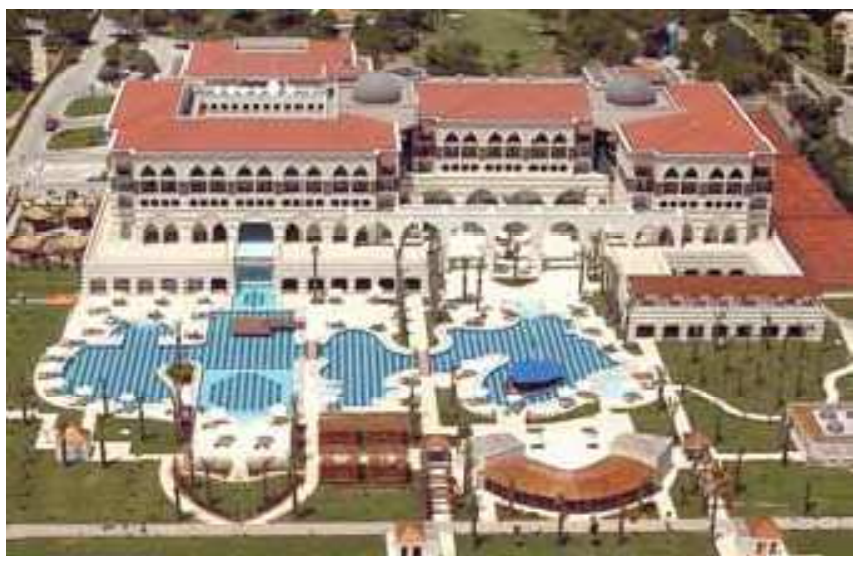

Figura 4- Turquia, Hotel Kempinski - The Dome, Antalya 


\section{ARTIGO TÉCNICO}

O complexo hoteleiro com 157 quartos, 16 moradias, seis restaurantes e três bares está localizado sobre uma área de aproximadamente $1.250 .000 \mathrm{~m}^{2}$.

Os quartos foram concebidos com base nas cores Mediterrâneas e estão equipados com o mais recente tecnologia. Não existem os típicos sinais "Por favor, não perturbar" em qualquer lugar do Kempinski. Esta informação, é por sua vez exibida na porta por um display LED, que pode ser convenientemente controlado pelo hóspede junto à cama.

\section{Quartos com Pensamento - Conforto Funções}

Uma tecnologia avançada e normalizada, sem um compromisso de um único fabricante e que proporciona-se conforto elevado ao utilizador e eficiência energética, foram as razões que levaram os investidores e operadores do Kempinski Hotels a optar pela tecnologia KNX. Durante o check-in dos hóspedes, a recepção poderá activar as seguintes funções do quarto seleccionado: A climatização definida para modo de conforto, luzes de boas-vindas e TV ligada. Todas as outras funções estarão operacionais mal o hóspede introduza o cartão no leitor do seu quarto.

\section{Ajuda Rápida em Caso de Emergência}

Todas as casas de banho estão equipadas com um sistema de chamada de emergência. Isso garante que a recepção será alertada através do sistema KNX com um alarme sonoro e a exibição do número do quarto no caso de uma emergência.

\section{- Áustria, Cidade de Salzburgo}

A cidade de Salzburgo cobre uma área de $65,65 \mathrm{~km}^{2}$ e tem 150.269 habitantes (conforme dados de 2007).

O sistema de iluminação pública da Cidade de Salzburgo inclui 19.000 luminárias com um total de 2,9 $\mathrm{MW}$ de potência e uma rede de $600 \mathrm{~km}$ de comprimento.

Os custos da energia por hora de funcionamento $(0,11 €$ por kW/h) são 319 euros.

O novo sistema KNX liga as luzes quando a luminosidade baixa os 180 lux e desliga a 40 lux na parte de manhã. Comutações devido ao mau tempo (tempestades, neve, nuvens) são ultrapassadas através do modo de longo tempo.

Os algoritmos do KNX verificam o desenvolvimento da luz natural em Salzburgo e só permitem que as luzes se liguem após um alargado período de escuridão, poupando assim uma grande quantidade de energia. A alta estabilidade do sistema KNX garante a segurança do sistema.

O sistema está construído em redundância. Existem dois sistemas idênticos a correr em paralelo, segundo o qual o sistema o primeiro sistema é executado como sistema primário. Se este sistema entra em modo de erro, o segundo sistema assume o controlo. Cada sistema auto verifica-se através da transmissão cíclica de mensagens de todos os KNX componentes para detectar avarias.

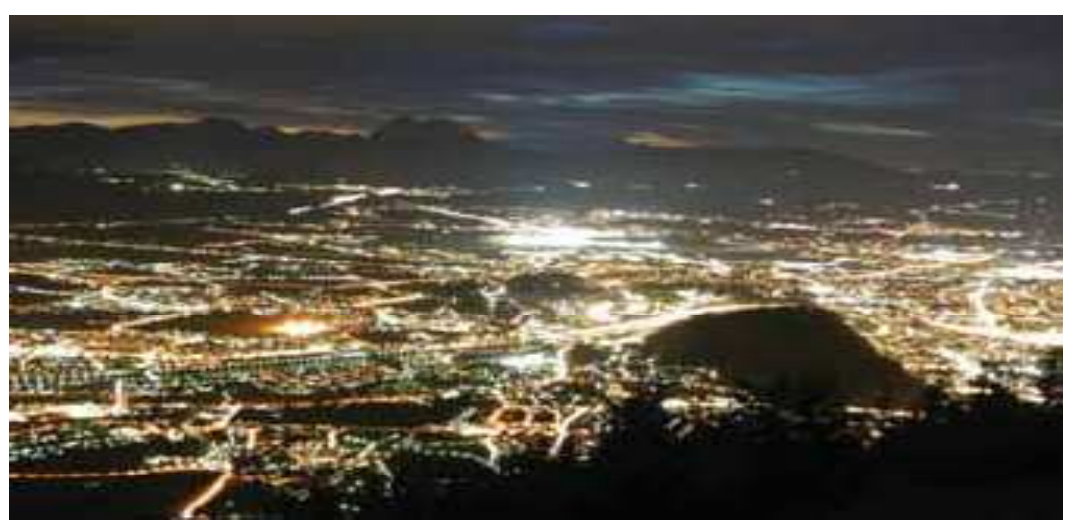

Figura 5 - Áustria, Central Publica de Iluminação de Salzburg 


\section{ARTIGO TÉCNICO}

Os algoritmos de controlo foram implementados módulos de funções KNX. Dois sensores luz estão localizados numa caixa metrológica aquecida e com a temperatura controlada. $\mathrm{O}$ circuito de equipamentos sensíveis à luz envia à noite um pré-aviso de 4 quatro minutos para a companhia eléctrica. Este pré-aviso é necessário para que o arranque e sincronização de um gerador de $4 \mathrm{MW}$. Todas as comutações seguintes serão desfasadas em 10 minutos para evitar picos de arranque e prevenir religações de iluminação.

Cada sistema permite um controlo manual, que se sobrepõe ao modo normal, durante a manutenção ou em circunstâncias especiais.

\section{Benefícios do Sistema KNX}

- Comutação automática do sistema de iluminação pública, poupando energia e aumentando os intervalos de manutenção para a mudança luzes.

- A automatização foi implementada com o KNX, porque um sistemas industriais equivalente SPS teria um custo muito superior. Os investimentos para componentes e engenharia foram de apenas $10.250 €$.

\section{- França, Cruzeiro MS Belle de l'Adriatique}

O MS Belle de l'Adriatique percorre o Mar Mediterrâneo desde da Costa da Croácia até às Ilhas Canárias.
O navio tem mais de 100 cabines em diferentes categorias e tem capacidade para mais de 200 passageiros.

Para além do elevado conforto, um grande navio de cruzeiro deve satisfazer todas as exigências no que diz respeito à segurança. A comutação da iluminação nos quartos, salões e corredores para a energia de emergência tem de ser efectuado num tempo muito curto. A tripulação do navio deve ter o controlo sobre esta funcionalidade em qualquer momento. Sendo a tecnologia KNX um sistema descentralizado, é o ideal para este tipo de aplicação.

\section{Conclusões}

Em edifícios utilizados para fins comerciais, a flexibilidade e a eficiência de custos desempenham um papel importante.

Neste enquadramento, o KNX apresenta-se como solução em virtude da sua flexibilidade e integração.

Factores como, flexibilidade, economia, segurança e conforto são alguns dos argumentos de KNX.

Funcionalidades tais como, gestão automática da iluminação, climatização, monitorização entre outras são soluções de integrantes do KNX.

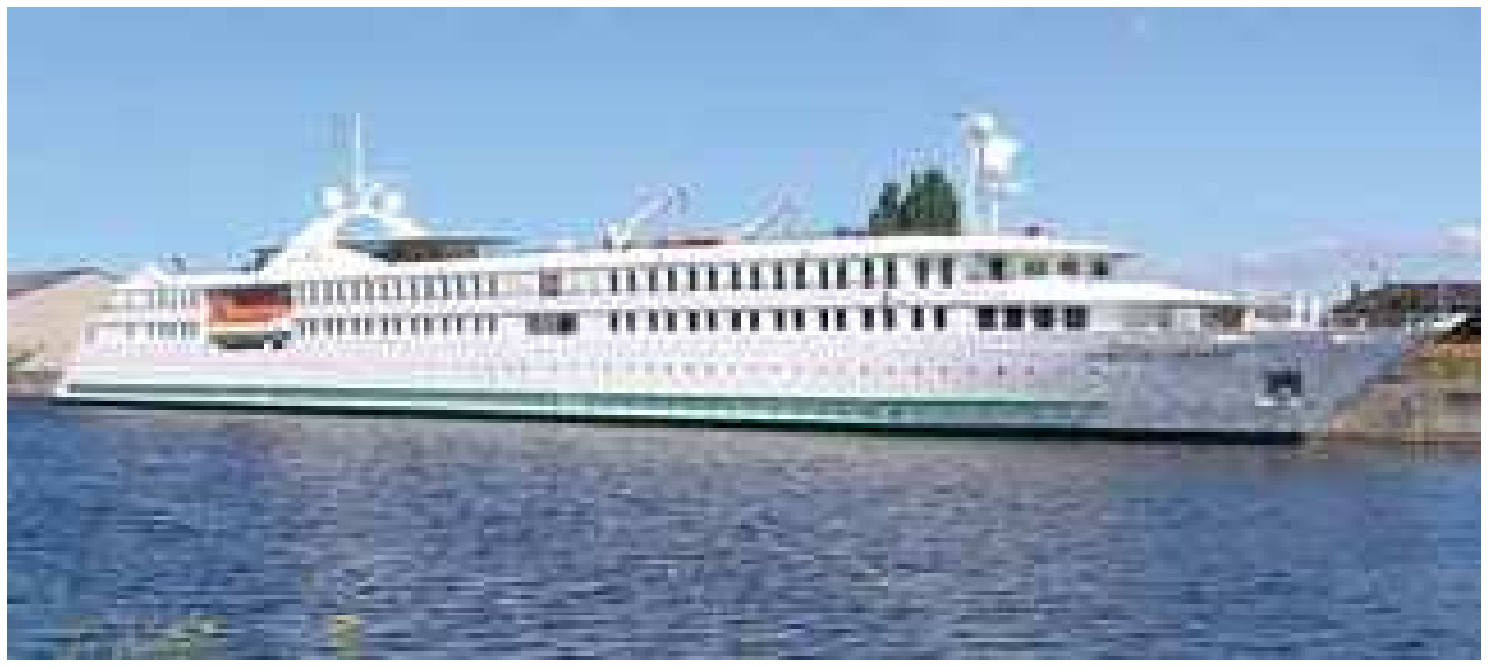

Figura 6- França, Cruzeiro MS Belle de l'Adriatique 